\title{
Photochemical reactivity of ancient marine dissolved organic carbon
}

\author{
Steven R. Beaupré ${ }^{1,2}$ and Ellen R. M. Druffel ${ }^{1}$ \\ Received 3 July 2012; revised 7 August 2012; accepted 9 August 2012; published 20 September 2012.
}

[1] Marine dissolved organic carbon (DOC) is the largest reservoir of reduced carbon in seawater and persists up to $4,000-6,000$ conventional radiocarbon $\left({ }^{14} \mathrm{C}\right)$ years on average. Photochemical degradation has been suggested as a geochemical sink for these long-lived molecules, yet there have been no studies relating photochemical lability to the ${ }^{14} \mathrm{C}$-ages of surface DOC. We observed apparent second order $\left(2^{\circ}\right)$ kinetics with respect to DOC and a strong trend from $\Delta{ }^{14} \mathrm{C}$-enriched to depleted values during exhaustive photomineralization of surface marine DOC with high energy UV light. Geochemically, these results suggest that surface DOC is an isotopically-heterogeneous mixture of molecules for which photochemical lability and ${ }^{14} \mathrm{C}$ ages are correlated. Photochemical mineralization may therefore be an important control on the persistence of ${ }^{14} \mathrm{C}$-depleted DOC in the ocean. Citation: Beaupré, S. R., and E. R. M. Druffel (2012), Photochemical reactivity of ancient marine dissolved organic carbon, Geophys. Res. Lett., 39, L18602, doi:10.1029/ 2012GL052974.

\section{Introduction}

[2] Marine dissolved organic carbon (DOC) is operationally defined as the carbon atoms in all organic molecules in seawater that are sufficiently small to pass through a filter with pore diameters of $\sim 0.2$ to $1 \mu \mathrm{m}$. Consequently, it is a heterogeneous collection of molecules varying in size, structure, and reactivity [Benner, 2002] that comprises the largest reservoir (662 Gt C globally) of reduced carbon in seawater [Hansell et al., 2009]. It is also one of the most persistent reservoirs, with radiocarbon $\left({ }^{14} \mathrm{C}\right.$, half-life $=5730 \pm 40$ years $)$ ages reaching up to 4,000 to 6,000 years on average in deep waters (>1000 m depth) of the central North Atlantic and Pacific Oceans [Bauer et al., 1992; Druffel et al., 1992; Williams and Druffel, 1987]. The majority of DOC is thought to originate from photosynthetic assimilation of dissolved inorganic carbon (DIC) in the surface ocean followed by export and aging within the ocean interior. Eventual migration of relict, deep DOC back to the surface ocean and mixing with recently produced material is hypothesized to account for bulk surface

\footnotetext{
${ }^{1}$ Department of Earth System Science, University of California, Irvine, California, USA.

${ }^{2}$ Now at Department of Geology and Geophysics, Woods Hole Oceanographic Institution, Woods Hole, Massachusetts, USA.

Corresponding author: S. R. Beaupré, Department of Geology and Geophysics, Woods Hole Oceanographic Institution, Woods Hole, MA 02543, USA. (sbeaupre@whoi.edu)

(C)2012. American Geophysical Union. All Rights Reserved. 0094-8276/12/2012GL052974
}

DOC that is isotopically "older" than surface DIC by ca. 300 $400 \%$ on the $\Delta^{14} \mathrm{C}$ scale [Beaupré and Aluwihare, 2010; Druffel et al., 1992; Williams and Druffel, 1987]. It is this return to sunlit waters and potential for photochemical degradation that has been hypothesized as a principle sink for the old DOC. Previously estimated fluxes assume that ${ }^{14} \mathrm{C}$-depleted DOC is both present and photochemically reactive in the surface ocean [Cherrier et al., 1999; Miller and Zepp, 1995; Mopper et al., 1991], yet there have been no corresponding studies relating DOC photochemical lability to ${ }^{14} \mathrm{C}$-age.

[3] Photochemically-produced dissolved inorganic carbon $\left(\mathrm{DIC}_{\mathrm{hv}}\right.$, i.e., $\left.\mathrm{CO}_{2}\right)$ is likely the major product of DOC photochemical degradation [Miller and Zepp, 1995; Mopper and Kieber, 2000; White et al., 2008]. However, analytical challenges associated with low production rates $(<1 \mu \mathrm{M} / \mathrm{hr})$ [White et al., 2008] and overwhelming concentrations of ambient DIC (ca. $2000 \mu \mathrm{M})$ currently preclude high-precision measurements of $\Delta^{14} \mathrm{C}$ values in $\mathrm{DIC}_{\mathrm{hv}}$ produced under natural sunlight. Therefore, we measured changes in concentrations and $\Delta^{14} \mathrm{C}$ values of successive fractions of $\mathrm{DIC}_{\mathrm{hv}}$ produced during repeated, brief $(\leq 90 \mathrm{~min})$ irradiations of DOC with high-intensity ultraviolet light [Beaupré et al., 2007] in order to constrain the photochemical reactivity of ancient DOC.

\section{Methods}

[4] Two seawater samples were collected with Niskin bottles from $20 \mathrm{~m}$ depth at Hydrographic Station $\mathrm{M}\left(34^{\circ} 50^{\prime} \mathrm{N}\right.$, $\left.123^{\circ} 00^{\prime} \mathrm{W}\right)$ [Smith and Druffel, 1998] in the eastern North Pacific Ocean on 28 October 2004. The samples were gravity filtered through $0.2 \mu \mathrm{m}$ Whatman Polycap AS capsules [White et al., 2008] into pre-combusted glass bottles, and stored frozen $\left(-20^{\circ} \mathrm{C}\right)$ until irradiated with UV-light in the laboratory via the serial-oxidation procedure of Beaupré et al. [2007].

[5] Briefly, the samples were acidified with $1 \mathrm{ml}$ of $85 \%$ $\mathrm{H}_{3} \mathrm{PO}_{4}$ and sparged with Helium to remove ambient DIC, then repeatedly subjected to brief irradiations ( $\leq 90 \mathrm{~min}$ ) from a $1200 \mathrm{~W}$ medium pressure mercury arc lamp for a cumulative irradiation time of 4 hours. $\mathrm{DIC}_{\mathrm{hv}}$ resulting from each irradiation was sparged from solution with Helium, collected cryogenically on a dedicated vacuum line, quantified manometrically, graphitized over iron catalyst [ Vogel et al., 1987], and isotopically-characterized via accelerator mass spectrometry (AMS). For comparison, bulk DOC concentrations and $\Delta^{14} \mathrm{C}$ values were measured by subjecting separate aliquots of these samples to single, continuous 4-hour irradiations [Beaupré et al., 2007]. Identical serialoxidations were performed on pre-irradiated, acidified Milli$\mathrm{Q}$ water with, and without, the addition of sucrose (IAEA 

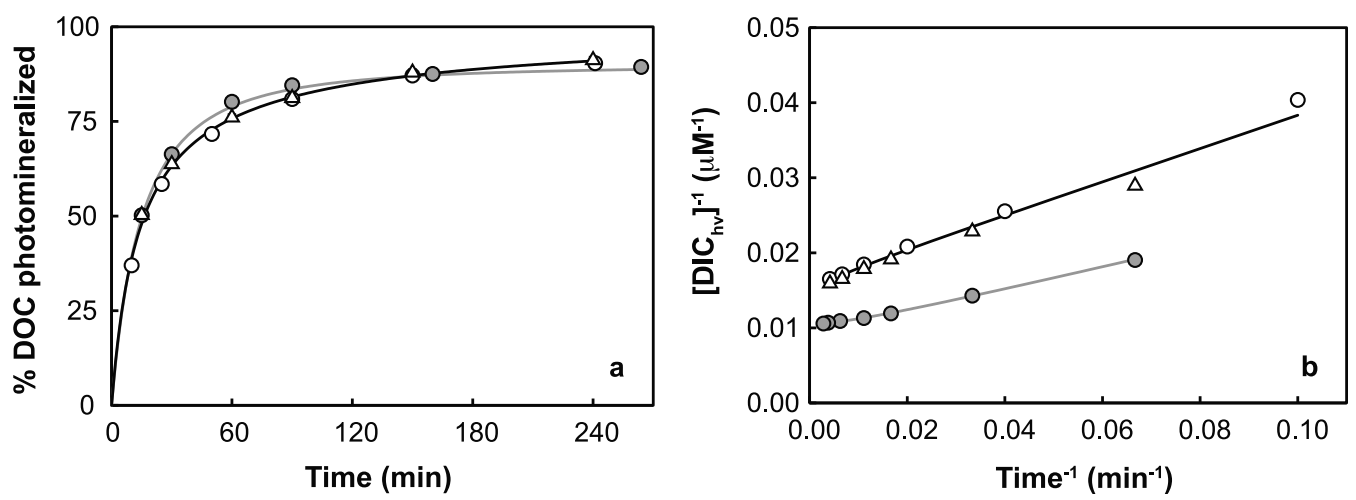

Figure 1. Photomineralization kinetics. Serial-oxidations plotted (a) as the cumulative percentages of DOC photomineralized as a function of time and (b) for bulk $2^{\circ}$ kinetics with respect to DOC (open circles and triangles denote replicate serialoxidations, $\mathrm{r}^{2}=0.988$, slope $=0.240 \pm 0.008 \mathrm{~min} \mu \mathrm{M}^{-1}$, intercept $=0.0154 \pm 0.0003 \mu \mathrm{M}^{-1}$ ) and sucrose (gray circles, $\mathrm{r}^{2}=0.996$, slope $=0.134 \pm 0.004 \min \mu \mathrm{M}^{-1}$, intercept $=0.0100 \pm 0.0001 \mu \mathrm{M}^{-1}$ ) according to equation (2). The black and gray curves in both panels are the trends predicted for DOC and sucrose, respectively, when modeled as binary mixtures in which both components react with $2^{\circ}$ kinetics as per equation (3). Error bars represent \pm 1 standard deviation and are predominantly obscured by the data points.

C-6) to serve as controls and to correct for the mass and isotope ratio of extraneous carbon introduced during analysis.

\section{Results}

\subsection{Serial-Oxidation Kinetics}

[6] Approximately $50 \%$ of the carbon was converted into $\mathrm{DIC}_{\mathrm{hv}}$ within the first 15 minutes of serial-oxidations for both the seawater samples and the sucrose solution (Figure 1a), with subsequent oxidations proceeding at monotonically decreasing rates. The reactions proceeded with apparent second order $\left(2^{\circ}\right)$ kinetics (equation (1)), demonstrating strong linearity (Figure 1b, $\mathrm{r}^{2}=0.988$ and 0.996 for DOC and sucrose, respectively) between inverse $\mathrm{DIC}_{\mathrm{hv}}$ concentrations $\left(1 /\left[\mathrm{DIC}_{\mathrm{hv}}\right]\right)$ and inverse elapsed irradiation time $(1 / \mathrm{t})$ according to the associated integrated rate expression (equation (2)), where $\mathrm{k}_{\text {bulk }}$ is the rate constant and [DOC] $]_{\mathrm{o}}$ is the initial concentration of DOC in solution (see auxiliary material for derivations). ${ }^{1}$

$$
\begin{gathered}
-\frac{d[D O C]}{d t}=k_{b u l k}[D O C]^{2} \\
\frac{1}{\left[D I C_{h v}\right]}=\left(\frac{1}{k_{b u l k}[D O C]_{o}^{2}}\right) \frac{1}{t}+\frac{1}{[D O C]_{o}}
\end{gathered}
$$

This reaction order differs from the first order $\left(1^{\circ}\right)$ kinetics assumed in most geochemical residence time calculations that use photolysis rates measured under natural sunlight [Mopper et al., 1991]. While this discrepancy may arise from the enhanced UV flux or altered chemical matrix (e.g., acidification, sparging $\mathrm{O}_{2}$ with $\mathrm{CO}_{2}$ ) in the reactor [Wang et al., 2009; White et al., 2008], we believe that the apparent $2^{\circ}$ kinetics are consistent with either secondary photochemical reactions or the superposition of $1^{\circ}$ reactions for unique molecular species in complex mixtures [Ho and Aris, 1987] such as DOC. Likewise, the initially homogeneous sucrose solution undoubtedly

${ }^{1}$ Auxiliary materials are available in the HTML. doi:10.1029/ 2012GL052974. became more complex as oxidized-intermediates populated the solution during photomineralization, leading to the superposition of reactions for a suite of molecules.

[7] Cumulatively, the serial-oxidations yielded $90 \pm 1 \%$ of the $\mathrm{DIC}_{\mathrm{hv}}$ expected from individual 4-hr oxidations of separate aliquots of DOC $(67.2 \pm 0.4 \mu \mathrm{M}, \mathrm{n}=2$; Table A1 in Text $\mathrm{S} 1$ of the auxiliary material). This pattern was highly reproducible (Figure 1a), with minor differences in DOC kinetics (Figure 1b, open circles and triangles) due to routine reactor maintenance that required UV-lamp replacement prior to replication. Based on a time-stepping numerical model of bulk $2^{\circ}$ mineralization (auxiliary material), less than $\sim 0.2 \%$ of the apparent losses could be attributed to the reduced photon flux from multiple lamp warm-up periods compared to an individual 4 hour irradiation. The principle losses of carbon during serial-oxidations were therefore attributed to the production of volatile oxidative-intermediates (e.g., CO) that escaped cryogenic trapping [Beaupré et al., 2007]. Such losses were not expected to significantly influence the mass-balance calculated $\Delta^{14} \mathrm{C}$ value of cumulatively extracted $\mathrm{DIC}_{\mathrm{hv}}$, assuming the proportion of carbon lost was approximately the same for all fractions.

\subsection{Serial-Oxidation $\Delta^{14} \mathrm{C}$ Values}

[8] Measured $\Delta^{14} \mathrm{C}$ values of individual $\mathrm{DIC}_{\mathrm{hv}}$ fractions from surface DOC decreased monotonically during the first 60 minutes of irradiation from $-217.0 \pm 2.6 \%$ at 10 minutes to a steady, mass-weighted average value of $-292.8 \pm 2.0 \%$ during the final 3 hours (Figure 2a). These deviations from the mean bulk $\Delta{ }^{14} \mathrm{C}$ value of $-252.1 \pm 1.7 \%(\mathrm{n}=2)$ cannot be attributed to radioactive decay because the half-life of ${ }^{14} \mathrm{C}$ is orders of magnitude longer than the duration of each serialoxidation. Nor can they arise from fractionation because the $\Delta^{14} \mathrm{C}$ values were corrected by concurrent AMS $\delta^{13} \mathrm{C}$ measurements by convention [Stuiver and Polach, 1977]. Furthermore, the invariant $\Delta^{14} \mathrm{C}$ values of serially-oxidized IAEA sucrose (Figure 2a) remained within uncertainty of the consensus value at the time of analysis $(+495.9 \pm 1.1 \%$ ) [Rozanski et al., 1992], substantiating isotopic fidelity in the transformation of organic matter to $\mathrm{DIC}_{\mathrm{hv}}$. Therefore, the decreasing $\Delta^{14} \mathrm{C}$ values in serially-oxidized DOC were due 

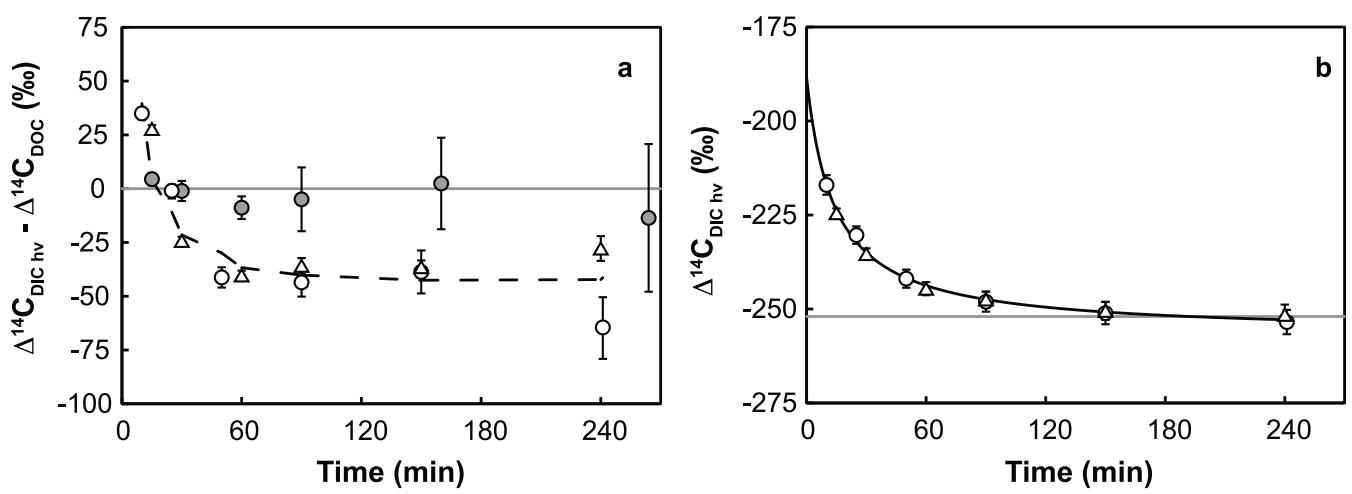

Figure 2. Isotopic evolution of photomineralized DOC. (a) The deviation between measured and expected $\Delta^{14} \mathrm{C}$ values of individual $\mathrm{DIC}_{\mathrm{hv}}$ fractions collected during photomineralization of $20 \mathrm{~m}$ DOC (open circles and triangles denote replicate serial-oxidations) and sucrose (gray circles) as a function of time. The dashed and gray lines represent the estimated isotopic trajectory of individual fractions from DOC and sucrose, respectively, calculated via equation (5). (b) Cumulative $\Delta^{14} \mathrm{C}$ values of $\mathrm{DIC}_{\mathrm{hv}}$ produced from $20 \mathrm{~m}$ DOC. The horizontal gray line represents the average $\Delta^{14} \mathrm{C}$ value of $20 \mathrm{~m}$ DOC measured on two separate aliquots with a single 4 hour irradiation, while the solid black curve is the non-linear least-squares regression of both trials based on equation (5). Error bars represent \pm 1 standard deviation propagated from uncertainties in manometry and AMS measurements.

to simultaneous mineralization of isotopically-distinct constituents that differed in photochemical lability. Specifically, the $\Delta^{14} \mathrm{C}$-enriched molecules must have possessed more photochemically labile carbon, on average, than the $\Delta^{14} \mathrm{C}$ depleted molecules in order to produce the decreasing trend. This implies that the measured $\Delta^{14} \mathrm{C}$ value of each $\mathrm{DIC}_{\mathrm{hv}}$ fraction was the average of a unique mixture determined by the extent of the reaction.

\section{Discussion}

[9] While a potentially limitless number of age-distributions may be employed [Bauer, 2002], previous analyses of marine DOC concentration and $\Delta^{14} \mathrm{C}$ depth profiles demonstrate remarkable consistency with a simple two-component model [Beaupré and Aluwihare, 2010; Mortazavi and Chanton, 2004; Williams and Druffel, 1987]. Assuming both components are complex mixtures that also react with apparent $2^{\circ}$ kinetics, the expected concentration of $\mathrm{DIC}_{\mathrm{hv}}$ cumulatively produced from simultaneous photomineralization as a function of time (equation (3)) is derived by adding their integrated rate expressions (auxiliary material).

$$
\left[D I C_{h v}\right]_{t}=\frac{A C t^{2}+D t}{A t^{2}+B t+1}
$$

In this combined integrated rate expression, the constants $\mathrm{A}$, $\mathrm{B}, \mathrm{C}$, and $\mathrm{D}$ are functions of the initial concentrations and $2^{\circ}$ rate constants for each component. Coefficients $\mathrm{C}$ and $\mathrm{D}$ are equal to the initial concentration of DOC and the initial rate of reaction, respectively, and therefore have physical meaning in the context of this reaction. Non-linear least-squares regression demonstrated good agreement between this combined integrated rate expression and DOC photomineralization $\left(\mathrm{r}^{2}=0.993\right.$ and 0.999 , black and gray curves, respectively, Figures $1 \mathrm{a}$ and $1 \mathrm{~b}$ ). In addition, the $67.4 \pm 22.7 \mu \mathrm{M}$ value of coefficient $\mathrm{C}$ returned by regression was equal to the independently measured concentration of DOC $(67.2 \pm 0.4 \mu \mathrm{M})$. Furthermore, the MacLaurin series expansion of equation (3) at $1 / t=0$ (i.e., as the reaction approaches completion) reduces to equation (2), providing concordance between the apparent linearity observed in Figure $1 \mathrm{~b}$ and the slight curvature expected from equation (3) (auxiliary material). While more complex models may be applied, these results suggest that the production of $\mathrm{DIC}_{\mathrm{hv}}$ in this reaction can be effectively modeled as the simultaneous $2^{\circ}$ mineralization of twocomponents.

[10] Geochemically, reaction orders in excess of unity complicate the interpretation of a simple residence time with respect to photochemical mineralization because this metric is derived assuming $1^{\circ}$ processes $[\mathrm{Li}, 1977]$. Furthermore, the "half-life" with respect to $2^{\circ}$ photochemical mineralization of a fraction of DOC will continue to increase as the concentration of that fraction decreases with exposure to light. For example, if $2^{\circ}$ kinetics also apply to natural environments, then extrapolating a reported $51 \mathrm{nM} \mathrm{hr}^{-1}$ net photochemical mineralization rate [White et al., 2008] with $2^{\circ}$ rather than $1^{\circ}$ kinetics would require $2,050 \%$ more sunlight exposure (i.e., $1.4 \times 10^{5}$ hours compared to $6.3 \times 10^{3}$ hours) to mineralize $99 \%$ of a $70 \mu \mathrm{M}$ hypothetical fraction of DOC in midlatitude surface waters, with all other parameters being equal (auxiliary material). Although conditions in this reactor (e.g., $\mathrm{pH},\left[\mathrm{O}_{2}\right]$, UV flux, temperature) differ from those in the surface ocean, the possibility of higher photomineralization reaction orders under natural sunlight presents a potentially important control on the persistence and origins of relict DOC in the marine environment.

[11] The $\Delta^{14} \mathrm{C}$ values of $\mathrm{DIC}_{\mathrm{hv}}$ cumulatively produced by simultaneous $2^{\circ}$ photomineralization of both components (subscripts $\mathrm{x}$ and $\mathrm{y}$ ) in this reaction are governed by conservation of mass.

$$
\Delta^{14} C_{D I C-h v}=\frac{\Delta^{14} C_{x}\left[D I C_{h v}\right]_{x}+\Delta^{14} C_{y}\left[D I C_{h v}\right]_{y}}{\left[D I C_{h v}\right]_{x}+\left[D I C_{h v}\right]_{y}}
$$

The time-dependence of these $\Delta^{14} \mathrm{C}$ values (equation (5)) may therefore be predicted by substituting integrated $2^{\circ}$ rate 
expressions for the concentrations of $\mathrm{DIC}_{\mathrm{hv}}$ evolved from each component into equation (4) (auxiliary material).

$$
\Delta^{14} C_{D I C-h v}=\Delta^{14} C_{D O C_{o}}+\frac{1}{m t+b}
$$

Non-linear regression demonstrated good agreement between the cumulative $\mathrm{DIC}_{\mathrm{hv}} \Delta^{14} \mathrm{C}$ values of serially-oxidized DOC and the hyperbolic relationship predicted by equation (5) $\left(\mathrm{r}^{2}=0.995\right.$, black curve, Figure $\left.2 \mathrm{~b}\right)$. In addition, the bulk DOC $\Delta^{14} \mathrm{C}$ value determined by non-linear regression $\left(\Delta^{14} \mathrm{C}_{\mathrm{DOC}, \mathrm{o}}=-256.6 \pm 1.7 \%\right.$ ) agreed with the average final cumulative value from both serial-oxidations $(-252.5 \pm 2.1 \%)$ and the average value of bulk DOC measured independently on separate aliquots (mean $\Delta{ }^{14} \mathrm{C}=$ $-252.1 \pm 1.7 \%$ ). Therefore, the observed evolution of $\Delta^{14} \mathrm{C}$ values can be effectively modeled as the simultaneous $2^{\circ}$ photomineralization of two-components.

[12] The regression coefficients $m$ and $b[(1.05 \pm 0.23) \times$ $10^{-3} \%^{-1} \mathrm{~min}^{-1}$ and $(14.7 \pm 2.2) \times 10^{-3} \%^{-1}$, respectively] from equation (5) are complex functions of the initial concentrations, rate constants, and isotope ratios of each DOC component. Although these coefficients, in combination with equations (3) and (4), could be used to estimate the composition of each component in principle, inherent uncertainties associated with the low serial-oxidation yields precluded robust numerical estimates. However, the $\Delta^{14} \mathrm{C}$ values of these components may be constrained as follows. First, the strong correlation between photochemical lability and $\Delta^{14} \mathrm{C}$ values implies that the average minimum $\Delta^{14} \mathrm{C}$ value observed for $20 \mathrm{~m}$ DOC $(-291.1 \pm 2.0 \%)$ represents an upper limit for the most $\Delta^{14} \mathrm{C}$-depleted, photochemically refractory molecules, while the $\Delta^{14} \mathrm{C}$-enriched initial fraction $(-217.0 \pm 2.6 \%$ o represents a lower limit for the most enriched, photochemically labile molecules. Second, the maximum $\Delta{ }^{14} \mathrm{C}$ value of $\mathrm{DIC}_{\mathrm{hv}}$ at the onset of photomineralization may be calculated to be $-189 \pm 10 \%$ (i.e., the limit of equation (5) as $t$ approaches 0 minutes). This value is numerically equivalent to the average isotope ratio of both components weighted by their initial reaction rates, and therefore represents the theoretical lower limit for the most labile, $\Delta^{14} \mathrm{C}$ enriched component. Third, mass balance arguments demonstrate that the asymptotic $-292.8 \pm 2.0 \% \Delta^{14} \mathrm{C}$ value of individual $\mathrm{DIC}_{\mathrm{hv}}$ fractions is limited by the $\Delta^{14} \mathrm{C}$ value of residual DOC as the reaction approaches completion (equation (6) and supplementary note).

$$
\lim _{t \rightarrow \infty} \Delta^{14} C_{D O C}=\frac{\Delta^{14} C_{x} k_{y}+\Delta^{14} C_{y} k_{x}}{k_{x}+k_{y}}
$$

That is, the final $\mathrm{DIC}_{\mathrm{hv}}$ fractions evolved from residual DOC with $\Delta^{14} \mathrm{C}$ values in a nearly constant blend dominated by the isotopic signature of the least reactive component (i.e., smallest rate constant). Therefore, $-292.8 \pm 2.0 \%$ represents an upper limit rather than the actual value of the least reactive, $\Delta^{14} \mathrm{C}$-depleted component.

[13] Neither the measured extrema $(-217.0 \pm 2.6 \%$ and $-292.8 \pm 2.0 \%$ ) nor the theoretical limits (e.g., $-189 \pm 10 \%$ and $-292.8 \pm 2.0 \%$ ) of $\mathrm{DIC}_{\mathrm{hv}} \Delta^{14} \mathrm{C}$ values approached the minimum expected range of end-member values anchored by surface DIC and mean deep DOC $(+53 \pm 20 \%$ and $-549 \pm 20 \%$ ) measured at Station M [Beaupré and Druffel, 2009]. Nor did they even remotely approach the disparate
$\Delta^{14} \mathrm{C}$ values constrained by Keeling plots $(+74 \pm 22 \%$ and $-1000 \%$ ) at Station M [Beaupré and Druffel, 2009], observations of neutral sugars (+47 to $67 \%$ ) [Repeta and Aluwihare, 2006] or lipid extracts (-551\%) [Loh et al., $2004]$ in surface DOC of the central North Pacific Ocean, or the strongly depleted values $(-834.9 \pm 4.3 \%$ of high molecular weight DOC emanating from hydrothermal vents [McCarthy et al., 2011]. While the seemingly attenuated range of observed $\mathrm{DIC}_{\mathrm{hv}} \Delta^{14} \mathrm{C}$ values ultimately results from differences in photochemical lability and subsequent isotopic mass balance, the two components dominating the serialoxidation trend (Figure 2) are not necessarily the same two components derived from a suite of biogeochemical processes acting on DOC over millennia.

[14] Therefore, the $\Delta^{14} \mathrm{C}$ trend observed during serialoxidation is more conservatively associated with differences in reactivity among chemical moieties rather than among complete molecules, indicating that photomineralization could, in principle, remove carbon from the old pool of DOC. Based on the spectrum of light from medium pressure $\mathrm{Hg}$ lamps and the near identity of kinetic curves for DOC and sucrose on a proportional scale (Figure 1a), carbon was likely oxidized with hydroxyl radicals produced by photolysis of water in the reactor. Assuming $\mathrm{DIC}_{\mathrm{hv}}$ produced at the onset of reaction $(-189 \pm 10 \%)$ was derived from a blend of recently produced $(+53 \pm 20 \%$ ) and relict (between $-1000 \%$ and $-549 \pm 20 \%$ ) DOC moieties, then a significant proportion $(23 \pm 2 \%$ to $40 \pm 4 \%)$ of the most labile constituent with respect to oxidation by hydroxyl radical was comprised of relict carbon based on mass balance (auxiliary material). While photomineralization of relict DOC is feasible by this mechanism, scaling these percentages to geochemical fluxes is chiefly precluded by large uncertainties in the proportions of $\mathrm{DIC}_{\mathrm{hv}}$ produced from bulk DOC by natural sunlight in the surface ocean via all known mechanisms. Similar reaction analyses under natural and simulated sunlight combined with numerical kinetics models are needed to further constrain estimates of the natural flux of relict $\mathrm{DIC}_{\mathrm{hv}}$.

[15] Acknowledgments. We thank John Southon and Guaciara dos Santos of the KCCAMS facility for radiocarbon measurements; Sheila Griffin, Ken Smith, the Captain and Crew of the R/V New Horizon for assistance in sample collection; Francois Primeau for advice on numerical methods; and Ollie Zafiriou for insightful comments on an early draft. The data reported in this paper are tabulated in the auxiliary material. This study was supported under NSF grant OCE-0961980 to E. R. M. Druffel.

[16] The Editor thanks Behzad Mortazavi and an anonymous reviewer for their assistance in evaluating this paper.

\section{References}

Bauer, J. E. (2002), Carbon isotopic composition of DOM, in Biogeochemistry of Marine Dissolved Organic Matter, edited by D. A. Hansell and C. A. Carlson, pp. 405-453, Academic, San Diego, Calif., doi:10.1016/ B978-012323841-2/50010-5

Bauer, J. E., P. M. Williams, and E. R. M. Druffel (1992), Carbon-14 activity of dissolved organic carbon fractions in the north-central Pacific and Sargasso Sea, Nature, 357(6380), 667-670, doi:10.1038/357667a0.

Beaupré, S. R., and L. I. Aluwihare (2010), Constraining the two-component model of marine dissolved organic radiocarbon, Deep Sea Res., Part II, 57(16), 1494-1503, doi:10.1016/j.dsr2.2010.02.017.

Beaupré, S. R., and E. R. M. Druffel (2009), Constraining the propagation of bomb-radiocarbon through the dissolved organic carbon (DOC) pool in the northeast Pacific Ocean, Deep Sea Res., Part I, 56(10), 1717 1726, doi:10.1016/j.dsr.2009.05.008.

Beaupré, S. R., E. R. M. Druffel, and S. Griffin (2007), A low-blank photochemical extraction system for concentration and isotopic analyses of marine dissolved organic carbon, Limnol. Oceanogr. Methods, 5, 174-184, doi:10.4319/lom.2007.5.174. 
Benner, R. (2002), Chemical composition and reactivity, in Biogeochemistry of Marine Dissolved Organic Matter, edited by D. A. Hansell and C. A. Carlson, pp. 59-90, Academic, San Diego, Calif., doi:10.1016/ B978-012323841-2/50005-1.

Cherrier, J., J. E. Bauer, E. R. M. Druffel, R. B. Coffin, and J. P. Chanton (1999), Radiocarbon in marine bacteria: Evidence for the ages of assimilated carbon, Limnol. Oceanogr., 44(3), 730-736, doi:10.4319/lo.1999.44.3.0730.

Druffel, E. R. M., P. M. Williams, J. E. Bauer, and J. R. Ertel (1992), Cycling of dissolved and particulate organic matter in the open ocean, J. Geophys. Res., 97(C10), 15,639-15,659, doi:10.1029/92JC01511.

Hansell, D. A., C. A. Carlson, D. J. Repeta, and R. Schlitzer (2009), Dissolved organic matter in the ocean: A controversy stimulates new insights, Oceanography, 22(4), 202-211, doi:10.5670/oceanog.2009.109.

Ho, T. C., and R. Aris (1987), On apparent second-order kinetics, AIChE J., 33(6), 1050-1051, doi:10.1002/aic.690330621.

Li, Y.-H. (1977), Confusion of the mathematical notation for defining the residence time, Geochim. Cosmochim. Acta, 41(4), 555-556, doi:10.1016/ 0016-7037(77)90293-9.

Loh, A. N., J. E. Bauer, and E. R. M. Druffel (2004), Variable ageing and storage of dissolved organic components in the open ocean, Nature, 430(7002), 877-881, doi:10.1038/nature02780.

McCarthy, M., S. R. Beaupré, B. D. Walker, I. Voparil, T. P. Guilderson, and E. R. M. Druffel (2011), Chemosynthetic origin of 14C-depleted dissolved organic matter in a ridge-flank hydrothermal system, Nat. Geosci., 4, 32-36, doi:10.1038/ngeo1015.

Miller, W. L., and R. G. Zepp (1995), Photochemical production of dissolved inorganic carbon from terrestrial organic matter: Significance to the oceanic carbon cycle, Geophys. Res. Lett., 22(4), 417-420, doi:10.1029/94GL03344.

Mopper, K., and D. J. Kieber (2000), Marine photochemistry and its impact on carbon cycling, in The Effects of UV Radiation in the Marine Environment, edited by S. J. de Mora, S. Demers, and M. Vernet, pp. 101-129, Cambridge Univ. Press, Cambridge, U. K., doi:10.1017/CBO9780511535444.005.
Mopper, K., X. Zhou, R. J. Kieber, D. J. Kieber, R. J. Sikorski, and R. D. Jones (1991), Photochemical degradation of dissolved organic carbon and its impact on the oceanic carbon cycle, Nature, 353(6339), 60-62, doi:10.1038/353060a0.

Mortazavi, B., and J. P. Chanton (2004), Use of Keeling plots to determine sources of dissolved organic carbon in nearshore and open ocean systems, Limnol. Oceanogr., 49(1), 102-108, doi:10.4319/1o.2004.49.1.0102.

Repeta, D. J., and L. I. Aluwihare (2006), Radiocarbon analysis of neutral sugars in high-molecular-weight dissolved organic carbon: Implications for organic carbon cycling, Limnol. Oceanogr., 51(2), 1045-1053, doi:10.4319/1o.2006.51.2.1045.

Rozanski, K., W. Stichler, R. Gonfiantini, E. M. Scott, R. P. Beukens, B. Kromer, and J. van der Plicht (1992), The IAEA ${ }^{14} \mathrm{C}$ intercomparison exercise 1990, Radiocarbon, 34(3), 506-519.

Smith, K. L., and E. R. M. Druffel (1998), Long time-series monitoring of an abyssal site in the NE Pacific: An introduction, Deep Sea Res., Part II, 45(4-5), 573-586, doi:10.1016/S0967-0645(97)00094-5.

Stuiver, M., and H. A. Polach (1977), Discussion: Reporting of ${ }^{14} \mathrm{C}$ data Radiocarbon, 19(3), 355-363.

Vogel, J. S., D. E. Nelson, and J. R. Southon (1987), ${ }^{14} \mathrm{C}$ background levels in an accelerator mass spectrometry system, Radiocarbon, 29(3), 323333.

Wang, W., C. G. Johnson, K. Takeda, and O. C. Zafiriou (2009), Measuring the photochemical production of carbon dioxide from marine dissolved organic matter by pool isotope exchange, Environ. Sci. Technol., 43(22), 8604-8609, doi:10.1021/es901543e.

White, E. M., D. J. Kieber, and K. Mopper (2008), Determination of photochemically produced carbon dioxide in seawater, Limnol. Oceanogr. Methods, 6, 441-453, doi:10.4319/lom.2008.6.441.

Williams, P. M., and E. R. M. Druffel (1987), Radiocarbon in dissolved organic matter in the central North Pacific Ocean, Nature, 330(6145), 246-248, doi: $10.1038 / 330246 \mathrm{a} 0$ 